\title{
Effective combination of microgravimetry and geoelectrical methods in the detection of subsurface cavities in archaeological prospection - selected case-studies from Slovakia
}

Roman PAŠTEKA ${ }^{1, *}$, David KUŠNIRÁK ${ }^{1,5}$, Dennis WILKEN ${ }^{2}$, René PUTIŠKA ${ }^{1}$, Juraj PAPČO ${ }^{3}$, Dominika GODOVÁ ${ }^{4}$, Ivan ZVARA ${ }^{1}$, Ema NOGOVÁ ${ }^{1}$, Lenka ONDRÁŠOVÁ ${ }^{1}$

${ }^{1}$ Department of Applied and Environmental Geophysics, Faculty of Natural Sciences, Comenius University, Mlynská dolina, Ilkovičova 6, 84248 Bratislava, Slovak Republic

${ }^{2}$ Department of Geophysics, Institute for Geosciences, Christian-Albrechts University, Otto-Hahn-Platz 1, 24118 Kiel, Germany

${ }^{3}$ Department of Theoretical Geodesy, Faculty of Civil Engineering, Slovak University of Technology, Radlinského 11, 81005 Bratislava, Slovak Republic

${ }^{4}$ Division of Geophysics, Earth Science Institute of the Slovak Academy of Sciences, Dúbravská cesta 9, 84005 Bratislava, Slovak Republic

${ }^{5}$ GEODATA Group, Hans-Kudlich-Straße 28, 8700 Leoben, Austria

\begin{abstract}
This contribution is focused on a common utilization of microgravimetry (very precise and detailed gravimetry) and geoeletrical methods (ground penetrating radar and electric resistivity tomography) in the detection of subsurface cavities in non-destructive archaeological prospection. Both methods can separately detect such kind of subsurface objects, but their complementary and at the same time an eliminating aspect can be very helpful in the interpretation of archaeogeophysical datasets. These properties were shown in various published case-studies. Here we present some more typical examples. Beside this, we present here for a first time an application of the electric resistivity tomography in the interior of a building (a church) in Slovakia. We also demonstrate an example with an extremely small acquisition step in microgravity as a trial for the detection of cavities with very small dimensions - in this case small separated spaces for coffins as a part of the detected crypt (so called columbarium). Unfortunately, these cavities were too small to be reliably detected by the microgravity method. We have tried the well-known 3D Euler deconvolution method to obtain usable depth estimates from the acquired anomalous gravity field. Results from this method were in the majority of cases plausible (sometimes little bit too shallow), when compared with the results from the ground penetrating radar.
\end{abstract}

*corresponding author: e-mail: roman.pasteka@uniba.sk 
In one selected example, the 3D Euler solutions were too deep and in the present stage of study we cannot well explain this situation. In general, all presented results support an important role of common combination of several geophysical methods, when searching for subsurface cavities in non-destructive archaeological prospection.

Key words: archaeogeophysics, non-destructive prospecting methods, detection, interpretation

\section{Introduction}

Geophysical methods build an important and fundamental part of nondestructive detection methods in archaeological prospection (e.g. Clark, 1990; Gaffney and Gater, 2003; Linford, 2006). For the detection of subsurface cavities (large graves, tombs, crypts, cellars etc.), mainly geoelectrical methods have been and are commonly used. Among them, especially the GPR (Ground Penetrating Radar) and ERT (Electric Resistivity Tomography) can very well recognize subsurface cavities due to their intensive differences in geoelectrical properties to the subsurface. Since the air filled cavity gives a very distinct contrast of the physical parameters, either the relative dielectric permittivity or the conductivity. There were published several successful studies of this kind of application (e.g. Leucci, 2006; Negri and Leucci, 2006; Cataldo et al., 2012; Zielinski et al., 2019). Among other geophysical methods mainly the detailed and precise gravimetry (microgravimetry or microgravity method) proves high level of confidence in subsurface cavities detection. Cavities (hollow spaces) show intensive contrast in the density - even when these are filled by debris and/or water. There exist several examples of microgravimetric detection of subsurface cavities in non-destructive archaeological prospection (e.g. Blížkovský, 1979; Lakshmanan and Montlucon, 1987; Slepak, 1997; Pašteka and Zahorec, 2000; Mrlina et al., 2005; Padín et al., 2012; Sarlak and Aghajani, 2017). Very effective is the combination of geoelectrical and microgravimetric methods for cavities detection - there were published several examples of this combination in archaeological prospection (Pašteka et al., 2007, Panisova et al., 2012, 2013, 2016 and others). Mainly the combination of GPR and microgravimetry appears to be very efficient and balanced combination cavities are presented in 2D vertical GPR section with strong diffraction waves on the top of the cavity, in horizontal GPR sections as intensive re- 
flecting anomalies and in incomplete Bouguer anomalies maps as dominant minima (gravity lows) with negative amplitudes of several tens of $\mu$ Gals $\left(1 \mu \mathrm{Gal}=10^{-8} \mathrm{~m} / \mathrm{s}^{2}\right)$.

In our contribution we would like to summarize results and experiences of our research in this area and demonstrate on the showed case-studies the properties and limits of the use of microgravimetric and geoelectrical methods in subsurface cavities detection. We show and discuss here results obtained at three sites in Slovakia (interiors of three churches), where we have applied the discussed geophysical methods. For the realisation of GPR measurements, we have used the GSSI SIR-3000 equipment with $400 \mathrm{MHz}$ antenna and for ERT measurements an automated multielectrode system ARES manufactured by GF-Instruments has been utilized. Microgravity data acquisition was realised by means of multiple Scintrex CG-5 Autograv instruments, necessary geodetic work (determination of heights) has been done using a simple optical levelling instrument GEO Fennel No. 10. For the quantitative interpretation of microgravimetric data we have used the well-known 3D Euler deconvolution method (Reid et al., 1990; Pašteka et al., 2009), which gave us in two cases acceptable results and in one case a controversial depth estimate.

We show here also the first trial of the use of the ERT method in an interior of a building (church) and we also show an example of very detailed microgravimetric research for the detection of separated spaces for coffins in a crypt (testing an acquisition step of $0.2 \mathrm{~m}$ ).

\section{First case-study: microgravimetric and GPR research of the interior of St. Mary's church in Dolné Dubové, SW Slovakia}

This research was realised pursuant to the local authority demand and the main aim was detection of old architectonic features in the exterior and interior of the St. Mary's church in Dolné Dubové, a small village in SW Slovakia. Important phase of this survey was realized inside the church, mostly in a part of the aisle and in the presbytery (Fig. 1). GPR survey was realized with a $400 \mathrm{MHz}$ antenna on a set of acquisition lines, separated $30 \mathrm{~cm}$ from each other. Acquired data were processed in the ReflexW software (Sandmeier, 2019). Main processing steps comprised: subtraction of 

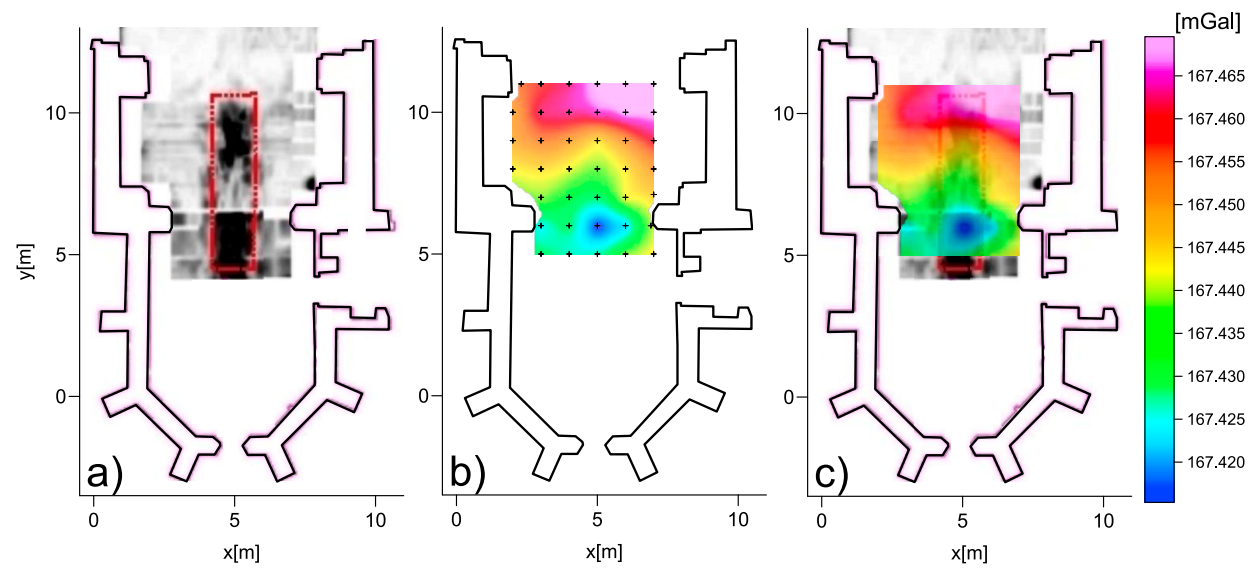

Fig. 1. Results from the GPR and microgravity method from the interior of St. Mary's church in Dolné Dubové, SW Slovakia. a) Horizontal GPR reflection map for the penetration depth of $90 \mathrm{~cm}$, red dotted rectangle shows strongest reflection amplitude anomaly. b) Coloured image map of incomplete Bouguer anomalies for the correction density $2.0 \mathrm{~g} / \mathrm{cm}^{3}$ (blue colour detects the minimum of the anomalous field); small crosses represent positions of gravity acquisition points. c) Common figure of both geophysical fields with transparent map of incomplete Bouguer anomalies.

the mean value (dewow), correction of the start-time, bandpass frequency filtering, gain adjustment, background removal and interpolation of the 2D radargrams into a 3D model. Results were displayed in a form of horizontal reflection amplitude maps for different penetration depths (example for the depth $90 \mathrm{~cm}$ is displayed in Fig. 1a, c). Microgravity data acquisition was realized in a net of points $1 \times 1 \mathrm{~m}$ by means of a Scintrex CG-5 gravimeter (serial number 155). Acquired data we processed in the usual way for micogravity surveys (e.g. Pašteka et al., 2007; Panisova et al., 2012): instrument drift correction, recalculation to base-point value (to a selected relative value), free-air and planar Bouguer corrections, building effects calculation and interpolation into horizontal maps of incomplete Bouguer anomalies. Correction for the gravity effect of the building (building effects calculation) was realized by means of an approximation of set of 3D vertical prisms with polynomial footprint (Cady, 1980; Potent modelling software User's guide, 2019). Results were displayed in a form of incomplete Bouguer anomalies map for the correction density $2.0 \mathrm{~g} / \mathrm{cm}^{3}$ (Fig. 1b, c). Acquired area by means of microgravimetry was smaller than that by the GPR 
method (Fig. 1) due to limited time-schedule for its realisation in the field.

In the results from the GPR method (horizontal amplitude sections) the most important reflection amplitude anomaly from a detected large object has an approximate rectangular shape and it is positioned in a typical place for a crypt - in the central part of the aisle and its transition to the presbytery (red dotted rectangle in Fig. 1a). It can be split in two parts a possible entering corridor and the main room of the crypt. Both parts start to be manifested at depths of approx. $0.5 \mathrm{~m}$ and continue down to approx. $2 \mathrm{~m}$. In the incomplete Bouguer anomalies map (Fig. 1b,c) the detected cavity (crypt) is demonstrated by a well-developed local minimum

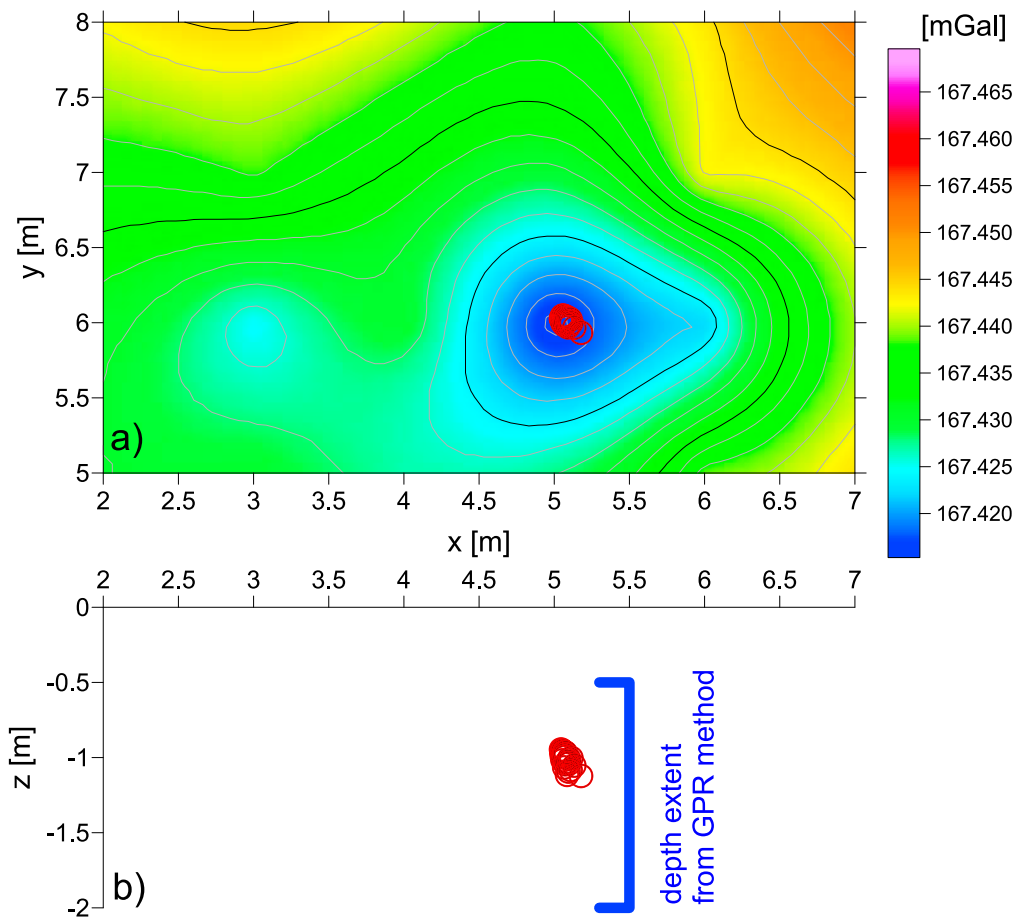

Fig. 2. Results from the 3D Euler deconvolution method, applied on the important negative anomaly from the microgravimetry (interior of St. Mary's church in Dolné Dubové). Used structural index value was $N=2$ (centre of a sphere in gravimetry). a) Planar visualisation of the result - cluster of the Euler depth solutions is concentrated in the centre of the anomaly, b) vertical section with the displayed cluster of Euler depth solutions (average depth $=1 \mathrm{~m}$ ). Depth extent (vertical interval) of the detected crypt from the GPR method was: approx. 0.5-2 m (thick blue segment line in the vertical section). 
with an amplitude of approx. $-40 \mu$ Gals over the lower part of the cavity, detected by the GPR method (local coordinates of the centre: $x=5 \mathrm{~m}$, $y=6 \mathrm{~m}$ ). The upper part of the GPR anomaly (for higher values of the coordinate $y$ ) is demonstrated only by a weak bending of the contours of the anomalous gravity field. This could correspond to a cavity with smaller dimensions - maybe a corridor to the main crypt, which is positioned in the bottom part of the figure. Depth estimation of the source depth, realized by means of the 3D Euler deconvolution method (Reid et al., 1990) incorporating so called regularized derivatives (Pašteka et al., 2009) gives a cluster of depth-solutions (Fig. 2) with an average depth of approx. $1 \mathrm{~m}$. This should give approximately the depth of the centre of the cavity. This result is little bit shallower in comparison with the result from the GPR method (approx. $1.5 \mathrm{~m}$ ). Our experiences from the applications of the 3D Euler deconvolution method are consistent with this result (Pašteka et al., 2011). This crypt was not verified by means of any archaeological excavation or video-inspection.

\section{Second case-study: microgravimetric, ERT and GPR re- search of the interior of St. Catherine's church in Banská Štiavnica, central Slovakia}

Based on a discussion with local historians and local cultural heritage experts, a complex geophysical survey was realized in the frame of several international geophysical summer schools in collaboration with the Department of Geophysics, Institute of Geosciences, Christian-Albrechts University in Kiel, Germany. The major part of the aisle and a part of the presbytery (beside the places with large wooden banks) was covered by GPR and microgravity measurements. Gravity measurements could be realized also in the close vicinity of the altar, GPR measurements unfortunately not (this is the reason, why these two methods do not cover identical areas, Fig. 3). Used instruments, data acquisition and processing methods were identical with that, described in the previous case-study. For this publication we have selected the most important part of the church - the transition between the aisle and the presbytery (Fig. 3), where both main methods (GPR and microgravity) detected an important cavity, with high probability a crypt. In the horizontal reflection amplitude section from the GPR method it is 

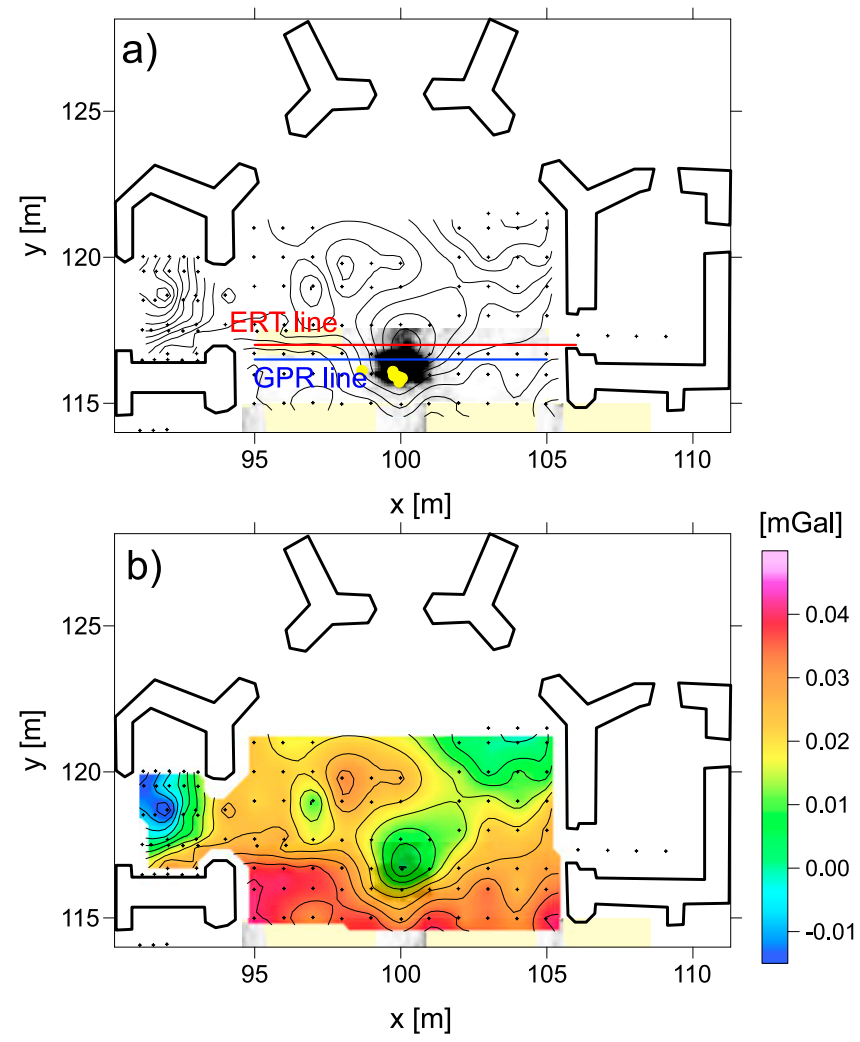

Fig. 3. Results from the GPR and microgravity method from the presbytery of St. Catherine's church in Banská Štiavnica, central Slovakia. a) Horizontal reflection amplitude map for the penetration depth of $50 \mathrm{~cm}$ together with contours of incomplete Bouguer anomalies. Red line segment shows the position of the realized ERT section inside the church, blue segment line is the position of selected vertical GPR section, showed in Fig. 5b. Yellow circles show positions of depth solutions, received from 3D Euler deconvolution method. b) Coloured contour image map of incomplete Bouguer anomalies for the correction density $2.0 \mathrm{~g} / \mathrm{cm}^{3}$ (in a medium transparent version).

characterized by a dominant symmetric anomaly in the centre of the figure (Fig. 3a). The anomalous gravity field (incomplete Bouguer anomalies for the correction density $2.0 \mathrm{~g} / \mathrm{cm}^{3}$ ) show a relatively complicated character - beside the central anomaly over the cavity of interest, there are also two intensive lows (negative anomalies) on the edges of the acquired area. These are connected with high probability with next cavities, positioned close to 
the walls (Fig. 3b), but this can be confirmed only by applying other geophysical methods in the future.

Central anomaly was also inspected by the ERT method - along a line at local $y$-coordinate $117 \mathrm{~m}$, crossing the manifestation of the cavity (Fig. 3a, red segment line). Separation distance of the electrodes was only $25 \mathrm{~cm}$ and the electrical contact between the electrodes and the floor was improved by a bentonite bed (for every single electrode outlet, Fig. 4). Tested methodology worked very well (electrical contact) and we have received sound results. From the commonly used concepts of ERT measurements, the Wenner-alpha, Schlumberger and dipole-dipole configuration have been used. Best results (best developed subsurface high resistivity anomalous feature) have been received for the dipole-dipole configuration (Fig. 5a), which is in confirmation with synthetic studies (e.g. Putiška et al., 2012). The well-known software RES2DINV for acquired ERT data inversion was

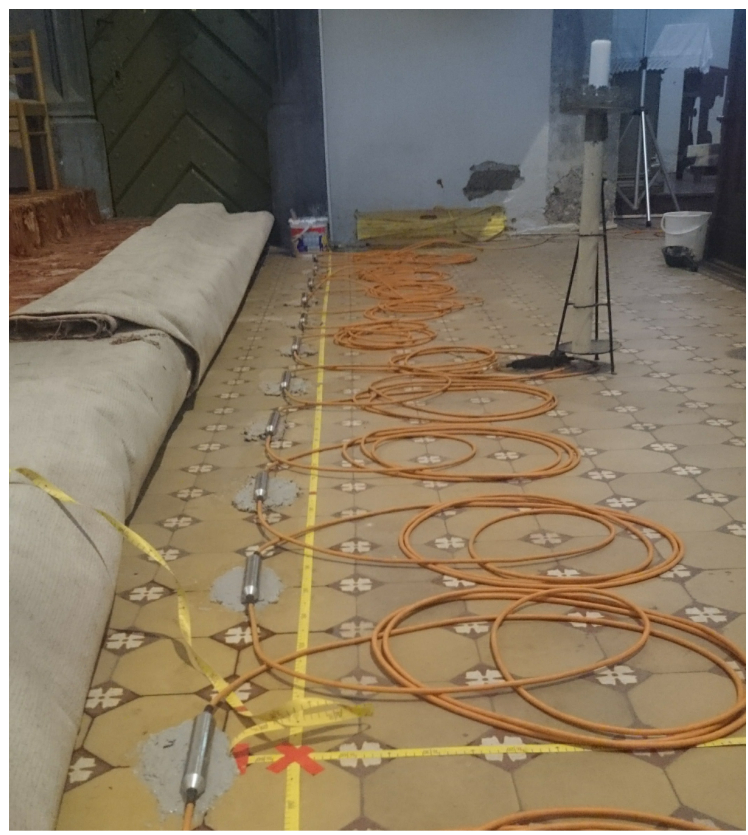

Fig. 4. Installation of the ERT electrodes section along a line inside the church of St. Catherine in Banská Štiavnica. Grounding conditions between the electrodes and the floor were improved by a bentonite bed (for every single electrode outlet). 
used (Loke, 2002). Result shows a relatively shallow structure in the central part of the profile (with the higher resistivity from $x=99.5$ to $x=100.7 \mathrm{~m}$, Fig. 5a), starting almost from the surface down to the depth of approx. $1.4 \mathrm{~m}$. There occurs also a local shallow high resistivity anomaly at $x=$ $99 \mathrm{~m}$, but we interpret it as a deformation of the section due to higher transient resistance at the group of electrodes at this place. The start of the depth extend of the main detected object is shallow, which means that the upper edge of the main cavity is probably positioned in a very small depth. This depth can be identical with the horizontal resolution of this section, which is very close to the separation of the electrodes $(0.25 \mathrm{~m})$.

These results are fully confirmed by the GPR results on a parallel line (Fig. 3a, blue segment line). As we can see in Fig. 5b, a dominant diffraction wave with the top at the TWT time (two-way travel time) of approx. $9 \mathrm{~ns}$ represents the upper edge of the main cavity. Converted into depths with an estimated velocity $8.5 \mathrm{~cm} / \mathrm{ns}$, (based on the analysis of selected diffrac-
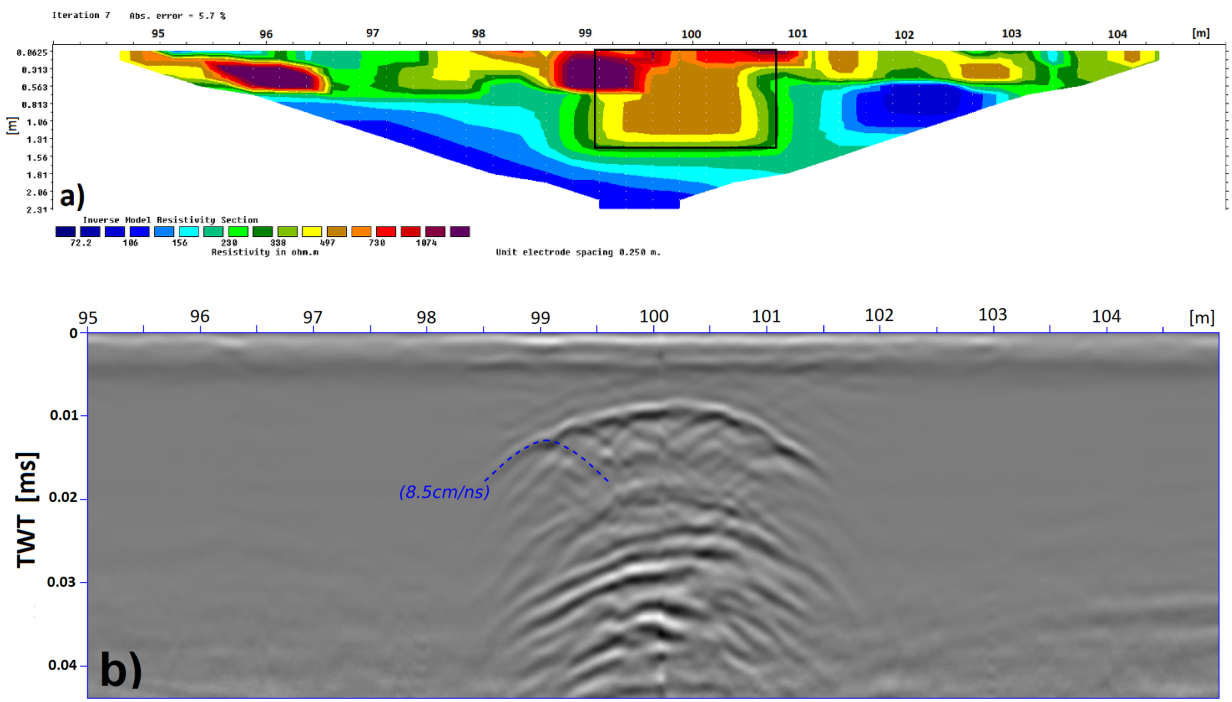

Fig. 5. Vertical sections from ERT (a) and GPR (b) methods along lines depicted in Fig. 3a. Inverted resistivity section (part a) was received after 7 iterations steps from the RES2DINV programme, for dipole-dipole configuration. Black rectangle represents the manifestation of the main interpreted cavity. In part b) in the vertical GPR section, there is depicted one selected local diffraction wave, used for the estimation of the penetration velocity $(8.5 \mathrm{~cm} / \mathrm{ns})$. 
tion hyperbola in the vertical section, Fig. 5b), it corresponds to a depth of approx. $40 \mathrm{~cm}$. Estimation of the bottom edge of this cavity is much more ambiguous, because of the deformation of propagating waves (partly also through the air in the cavity). A strong reflection can be identified at the TWT time of approx. $30 \mathrm{ns,} \mathrm{which} \mathrm{represents} \mathrm{a} \mathrm{depth} \mathrm{of} \mathrm{approx.} 130 \mathrm{~cm}$. Both estimations from the ERT and GPR methods give such a relatively small depth extent of this detected cavity (approx. from 0.3-0.4 to 1.3$1.4 \mathrm{~m}$ ), which corresponds more to a larger grave than to a crypt. Results from the 3D Euler deconvolution method are not as clear as in previous case. This depth estimation method was applied on the central anomaly from incomplete Bouguer anomalies (Fig. 3) - the average estimated depth of the cavity centre reaches approx. $1.6 \mathrm{~m}$, which is quite deep in comparison with the results from the geoelectrical methods. We cannot explain this situation - in the absolute majority of previous studies we had achieved a good coincidence of these methods (GPR and Euler method). Possibly, the central negative anomaly represents a combined effect of the crypt with an effect of a corridor, running in the direction to another cavity, positioned in the upper right corner of the presbytery (Fig. 3b), but this interpretation is very speculative and is not supported by GPR data in this part of the church. Explanation of this situation will be probably given in the future, when next GPR survey together with archaeological excavation or video-inspection will be performed.

\section{Third case-study: microgravimetric and GPR research of the interior of St. Joseph's church in Beckov, SW Slovakia}

In this third example we show results of GPR and microgravimetric research of the interior of St. Joseph's church in the village Beckov (SW Slovakia), which was realized in the frame of a voluntary work of teachers and students from the Department of applied and environmental geophysics, Comenius University in Bratislava in collaboration with Franciscan fraters from the monastery in Beckov. Both methods were focused on the area of the transition from the main aisle to the presbytery (Figs. 6 and 7), because here was expected an existence of the main crypt in this church. Used instruments, data acquisition and processing methods were identical with that, described in previous two case-studies. 
As it is nicely visible in the GPR horizontal reflection maps for various penetration depths (Fig. 6), a cavity with relatively complex structure was detected - it is composed from a major corridor and perpendicularly oriented separated spaces for positioning of coffins, so called columbarium. It is interesting to mention, that in our long year experience with geophysical
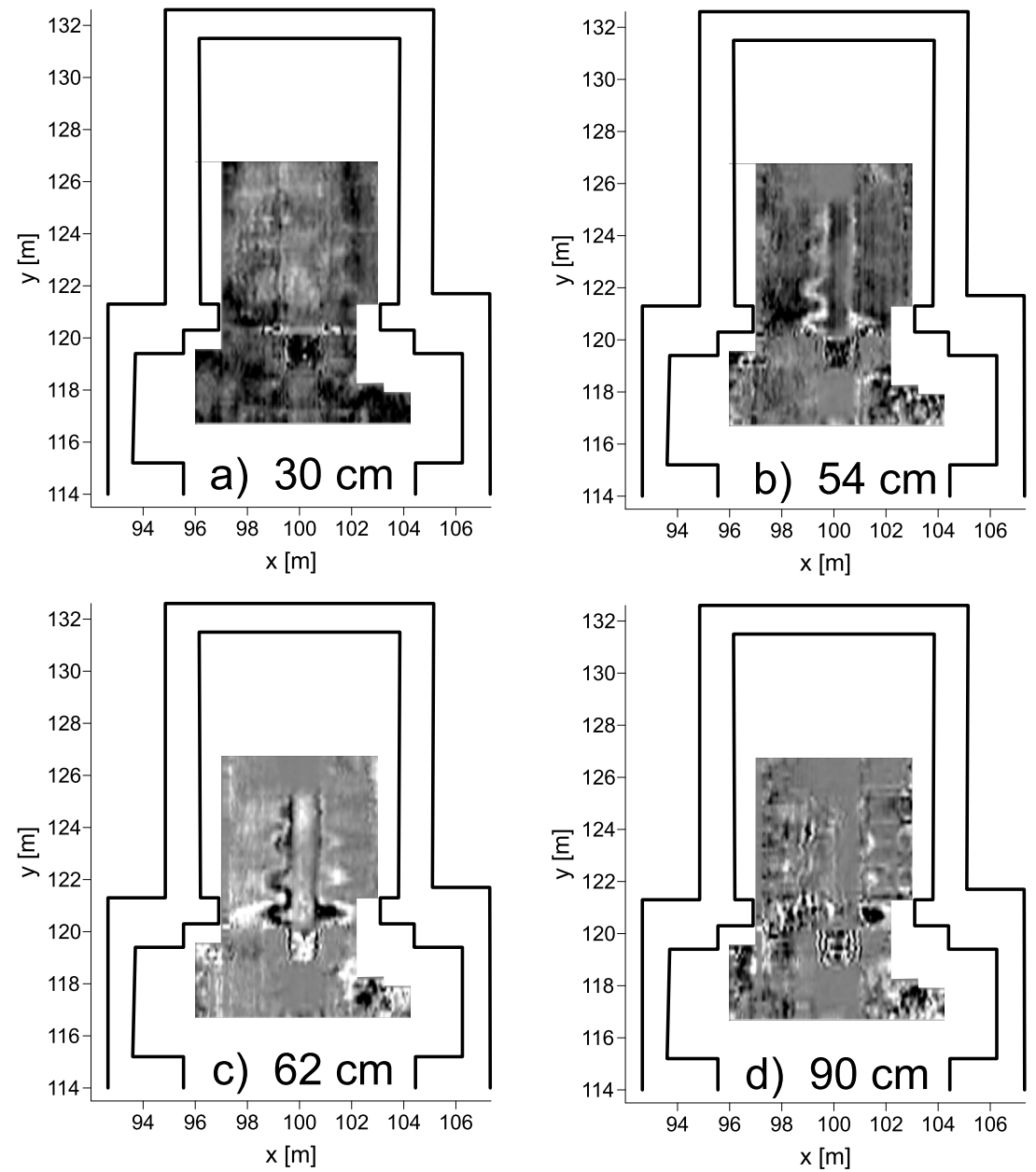

Fig. 6. Results from the GPR survey from the interior of St. Joseph's church in Beckov, SW Slovakia. a) Horizontal GPR reflection amplitude map for the penetration depth of $30 \mathrm{~cm}, \mathrm{~b}$ ) horizontal map for the penetration depth of $54 \mathrm{~cm}, \mathrm{c}$ ) horizontal map for the penetration depth of $62 \mathrm{~cm}, \mathrm{~d}$ ) horizontal map for the penetration depth of $90 \mathrm{~cm}$. 

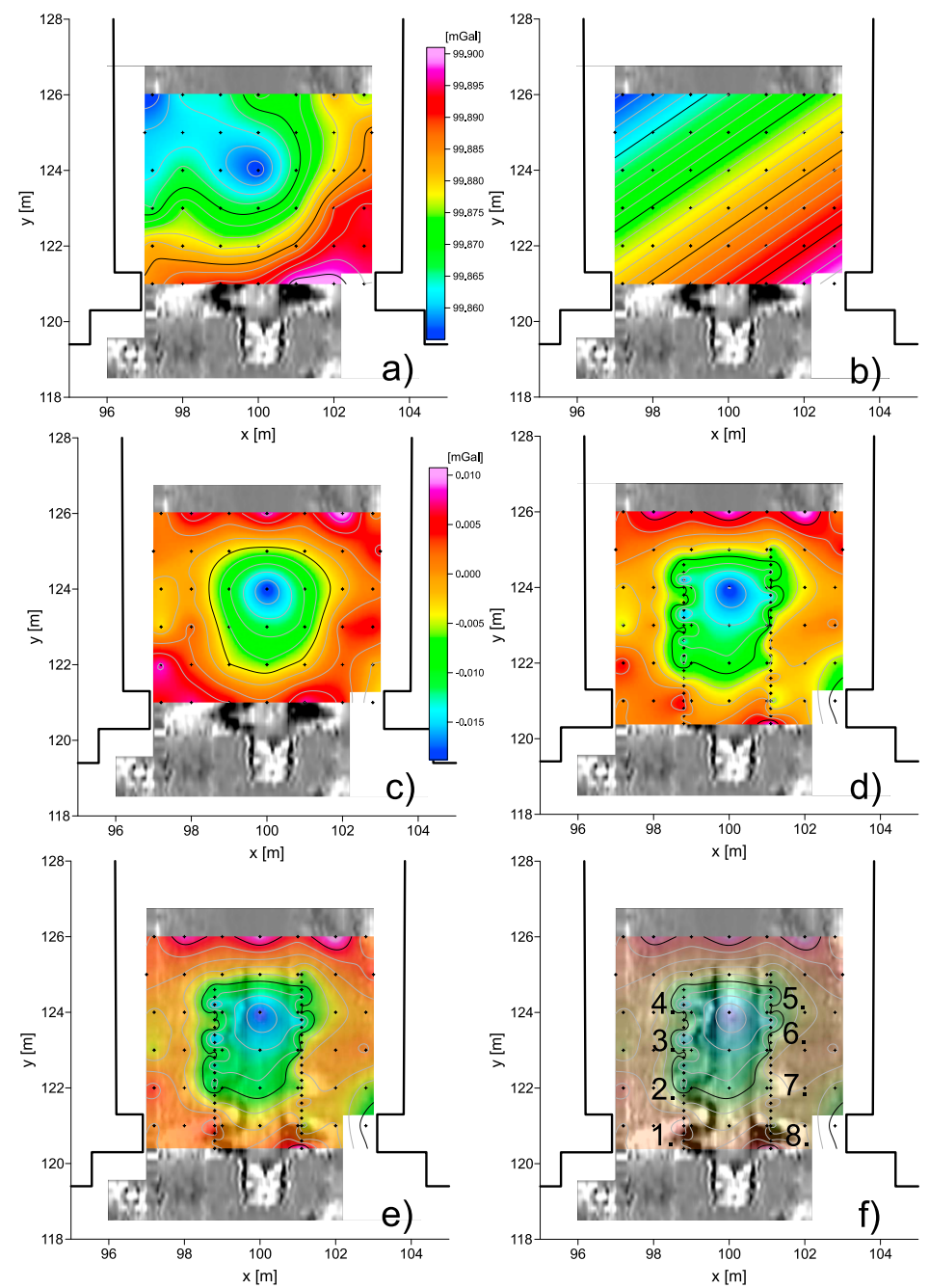

Fig. 7. Results from the microgravity survey from the interior of St. Joseph's church in Beckov, SW Slovakia. a) Coloured contour image map of incomplete Bouguer anomalies for the correction density $2.0 \mathrm{~g} / \mathrm{cm}^{3}$ calculated from $1 \times 1 \mathrm{~m}$ separated points, b) Map of the planar trend, obtained from the field of incomplete Bouguer anomalies by means of LSQ method, c) Coloured contour image map of residual incomplete Bouguer anomalies, d) Coloured contour image map of residual incomplete Bouguer anomalies, calculated from $1 \times 1 \mathrm{~m}$ separated points together with detailed points $(0.2 \mathrm{~m}$ distance $)$ on two added lines, e) The same field from part (d), but displayed with medium transparency, f) The same field from part (d), but with high transparency together with order numbers of detected "coffin cavities" in the columbarium. 
data acquisition in historical objects and churches in Slovakia, this is the first occurrence of such a type of crypt or tomb, detected by means of the GPR method. The upper edge of this crypt appears in a relative shallow depth - of approx. $0.5 \mathrm{~m}$. For depths larger than approx. $1.4 \mathrm{~m}$ this structure (pattern) disappears from the horizontal GPR sections (not shown in this paper).

Microgravity survey could be realized only in a part of the presbytery (Fig. 7), because of technical problems with one of the used instruments. Beside this limitation (not the whole area of the columbarium could be covered), obtained results are interesting. In the first stage, this area was covered by a net of $1 \times 1 \mathrm{~m}$ points. Received incomplete Bouguer anomalies map (Fig. 7a) has a relatively strong trend in a diagonal direction, coming probably from deeper geological composition of the underground. This trend was constructed by means of planar regression (LSQ method) (Fig. 7b) and removed from the original field - the residual incomplete Bouguer anomalies map is displayed in Fig. 7c. In this map the complex columbarium structure is manifested as one simple cavity (one dominant negative anomaly) and the local separated spaces of coffins cannot be (of course) recognized. Beside this, the received residual field is deformed on its edges (because of a kind of edge effect, occurring during the linear trend removal) and only the central part of this field correctly reflects the presence of the cavity.

In the next step we have repeated the same procedure, but we have incorporated also two detailed lines $(x=98.8 \mathrm{~m}$ and $x=101.2 \mathrm{~m})$, along which the data acquisition was realized with a step of only $20 \mathrm{~cm}$ (Fig. 7d). As we can see in details in Figs. 7e and $7 \mathrm{f}$ (here the residual field map is displayed with higher transparency), incorporation of these detailed values helped to obtain more "rangy" anomalous field and some parts could be maybe identified with the local separated spaces for coffins (order numbers of anomalies Nr. 3, 4, 5 in Fig. 7f). More precise analysis of this result shows that these local deviations in the new anomalous field have very small amplitudes - very close to the outer precision of usual data acquisition with Scintrex CG-5 gravity meters (approx. $\pm 5 \mu$ Gals). This can be well demonstrated in graphs of residual incomplete Bouguer anomalies along these two detailed lines $(x=98.8 \mathrm{~m}$ and $x=101.2 \mathrm{~m})$, displayed in Fig. 8. Reader can see that achieved small amplitude negative anomalies have in the majority a random character and cannot be well synchronized with the positions of 
coffin spaces (with exception of anomalies Nr. 3 and 6), derived from GPR measurements (thick black segment lines with order numbers in bottom of graphs in Fig. 8). Gravitational effects, caused by the presence of such small cavities (coffin spaces) in their actual depth position have very small amplitudes and cannot be therefore detected by the used microgravimetric method (with the used instrument, sampling intervals and processing procedure). Depth of the source of the central negative anomaly (mainly from the corridor in the columbarium), obtained from the 3D Euler deconvolution method, was estimated with a value: $0.9 \mathrm{~m}$. When we compare this result with the results from the GPR method $(0.5-1.4 \mathrm{~m})$, solutions from 3D Euler deconvolution method are positioned in the first half and centre of the GPR values, which is also in this case consistent with our previous experiences with this method (e.g. Pašteka et al., 2011) and also from the results presented in the first case-study in this paper.
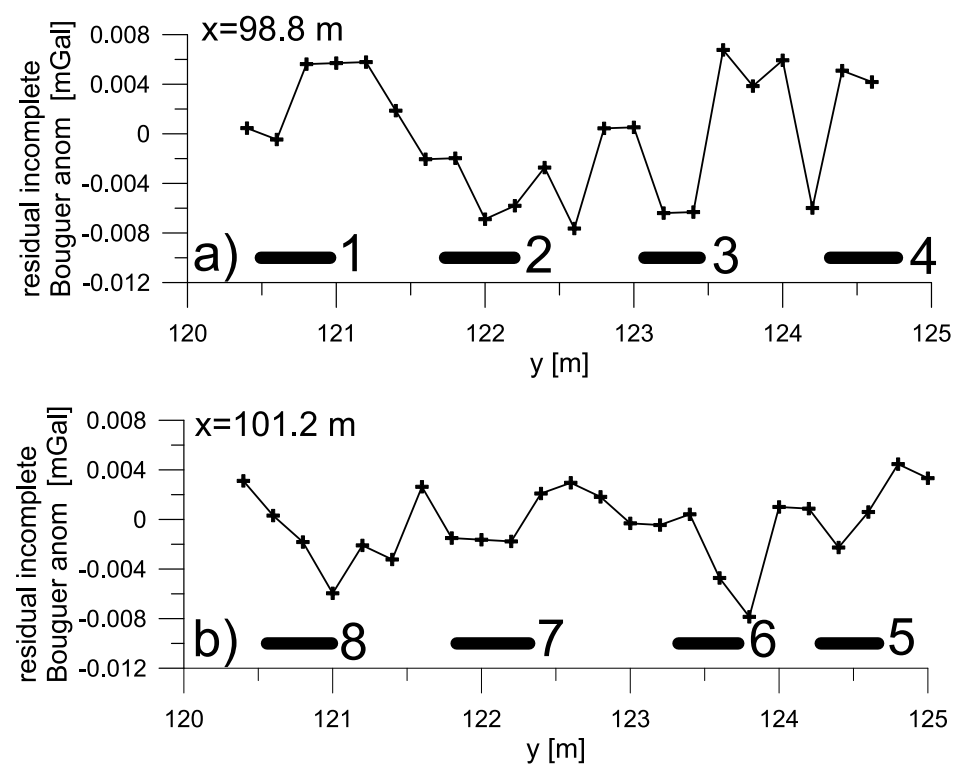

Fig. 8. Graphs of residual incomplete Bouguer anomalies (for the correction density $2.0 \mathrm{~g} / \mathrm{cm}^{3}$ ) along two detailed lines above the detected columbarium in the St. Joseph's church in Beckov (see Fig. 7d). a) Line along $x=98.8 \mathrm{~m}$, b) Line along $x=102.2 \mathrm{~m}$. Thick black horizontal lines with order numbers in bottom of both graphs represent the positions of coffin spaces (cavities) taken from the GPR method. 


\section{Conclusions}

We have shown in these three presented case-studies from various churches in SW and central Slovakia that the combination of microgravimetric and geoelectrical methods can be very effective in the detection and study of subsurface cavities such as crypts. Particularly the combination of GPR and microgravimetry is very useful and effective: cavities (crypts) are manifested in horizontal GPR sections as intensive reflectors and in incomplete Bouguer anomaly maps as dominant minima. In the St. Mary's church in Dolné Dubové one central crypt was found by GPR and by microgravity method (depth extent: approx. 0.5-2 m). In the St. Catherine's church in Banská Štiavnica a relatively shallow central cavity (crypt?) was found by GPR and ERT methods (depth extent: approx. 0.3-1.4 m). Anomalous gravity field has confirmed this position, but depth estimates from the Euler deconvolution methods gave larger depths (approx. $1.6 \mathrm{~m}$ ), which we cannot explain at this moment. In the St. Joseph's church in Beckov the GPR method has found a central crypt in the presbytery (in a form of so called columbarium) and microgravimetry has confirmed the presence of this crypt (but not the local coffin spaces in the columbarium).

We would like to emphasize two original points in this contribution:

1) We have realized, for the first time in Slovakia, ERT measurements inside a building in a completely non-invasive approach - in the St. Catherine's church in Banská Štiavnica. Separation distance of the electrodes was only $25 \mathrm{~cm}$ and the electrical contact between the electrodes and the floor ensured by applying a bentonite bed for every electrode outlet. The measurement system worked well and we have obtained a manifestation of relatively shallow cavity (crypt?) - in an almost identical position as obtained by the GPR method.

2) Also, for the first time, we have realized microgravimetric measurements with extremely small acquisition interval - only $20 \mathrm{~cm}$ (along two selected acquisition lines). This was realised in the church of St. Joseph in Beckov, where the GPR method has recovered a crypt with a relative complex structure - the so called columbarium (main crypt with perpendicularly oriented smaller separated spaces for placing the coffins). The result of this trial did not yield the expected results - anomalies caused by such small cavities are too small to be correctly detected by means of 


\section{microgravimetry.}

In general, we can state that the GPR method is faster in data acquisition, when compared to microgravity method. As for processing the acquired data the situation is opposite. The great advantage of the GPR method is the fact that it gives also the depth information, while in gravimetry this kind of information comes from the interpretation process (which can be often ambiguous). A good example are the results obtained from the applied 3D Euler deconvolution method, where the depth estimates in some cases are not realistic - here in the example of the St. Catherine's church in Banská Štiavnica the received depth estimates were too deep.

Acknowledgements. Authors would like to express their thanks to all our students and colleagues from the Christian-Albrechts University in Kiel and from the Comenius University in Bratislava, who helped us with the data acquisition. We would also like to thank Bruno Meurers for borrowing the Scintrex CG-5 instrument from the Department of Meteorology and Geophysics, Vienna University. Our thanks belong also to Franciscan fraters from the monastery in Beckov, who allowed us to perform measurements in the church of St. Joseph's, which belongs to their guardianship. Published research was supported by the Slovak scientific agency VEGA in the frame of project $1 / 0462 / 16$. Some methodical aspects have been solved also as a part of the scientific program in the frame of the COST Action SAGA: The Soil Science \& Archaeo-Geophysics Alliance - CA17131 (https://www.saga-cost.eu/), supported by COST (European Cooperation in Science and Technology).

\section{References}

Blížkovský M., 1979: Processing and applications in microgravity surveys. Geophys. Prospect., 27, 4, 848-861, doi: 10.1111/j.1365-2478.1979.tb01002.x.

Cady J. W., 1980: Calculation of gravity and magnetic anomalies of finite-length right polygonal prisms. Geophysics, 45, 10, 1507-1512, doi: 10.1190/1.1441045.

Cataldo R., D'Agostino D., Leucci G., 2012: Insights into the Buried Archaeological Remains at the Duomo of Lecce (Italy) Using Ground-penetrating Radar Surveys. Archaeol. Prospect., 19, 3, 157-165, doi : 10.1002/arp. 1423.

Clark A., 1990: Seeing Beneath the Soil: Prospecting Methods in Archaeology. Bathsford, $196 \mathrm{p}$.

Gaffney C., Gater J., 2003: Revealing the Buried Past: Geophysics for Archaeologists. Tempus, $192 \mathrm{p}$. 
Lakshmanan J., Montlucon J., 1987: Microgravity probes the Great Pyramid. Lead. Edge, 6, 1, 10-17, doi: 10.1190/1.1439319.

Leucci G., 2006: Contribution of Ground Penetrating Radar and Electrical Resistivity Tomography to identify the cavity and fractures under the main Church in Botrugno (Lecce, Italy). J. Archaeol. Sci., 33, 9, 1194-1204, doi: 10.1016/j.jas.2005.12 .009 .

Linford N., 2006: The application of geophysical methods to archaeological prospection. Rep. Prog. Phys., 69, 7, 2205-2257, doi : 10.1088/0034-4885/69/7/R04.

Loke M. H., 2002: Tutorial: 2-D and 3-D electrical imaging surveys. Manuscript, online, accessed 2019-11-20, available from: http://personales.upv.es/jpadin/course notes.pdf.

Mrlina J., Křivánek R., Majer A., 2005: Geophysical Survey in the St. Vitus Cathedral in Prague (Geofyzikální prùzkum k lokalizaci hrobky v katedrále sv. Víta v Praze). Castrum Pragense, 6, 105-124 (in Czech, English abstract).

Negri S., Leucci G., 2006: Geophysical investigation of the Temple of Apollo (Hierapolis, Turkey). J. Archaeol. Sci., 33, 11, 1505-1513, doi: 10.1016/j.jas.2006.02.003.

Padín J., Martín A., Anquela A. B., 2012: Archaeological microgravimetric prospection inside don church (Valencia, Spain). J. Archaeol. Sci., 39, 2, 547-554, doi : 10.1016/ j.jas.2011.10.012.

Panisova J., Pašteka R., Papčo J., Fraštia M., 2012: The calculation of building corrections in microgravity surveys using close range photogrammetry. Near Surf. Geophys., 10, 5, 391-399, doi: 10.3997/1873-0604.2012034.

Panisova J., Fraštia M., Wunderlich T., Pašteka R., Kušnirák D., 2013: Microgravity and Ground-penetrating Radar Investigations of Subsurface Features at the St. Catherine's Monastery, Slovakia. Archaeol. Prospect., 20, 3, 163-174, doi: 10.1002/arp .1450 .

Panisova J., Murín I., Pašteka R., Haličková J., Brunčák P., Pohánka V., Papčo J., Milo P., 2016: Geophysical fingerprints of shallow cultural structures from microgravity and GPR measurements in the Church of St. George, Svaty Jur, Slovakia. J. Appl. Geophys., 127 (April), 102-111, doi: 10.1016/j.jappgeo.2016.02.009.

Pašteka R., Zahorec P., 2000: Interpretation of microgravimetrical anomalies in the region of the former church of St. Catherine, Dechtice. Contrib. Geophys. Geod., 30, 4, $373-387$.

Pašteka R., Terray M., Hajach M., Pašiaková M., 2007: Microgravity measurements and GPR technique in the search for medieval crypts: a case study from the St. Nicholas church in Trnava, SW Slovakia. Proceedings of the Archaeological Prospection 7th conference in Nitra, Štúdijné zvesti, 41, 222-224.

Pašteka R., Richter F. P., Karcol R., Brazda K., Hajach M., 2009: Regularized derivatives of potential fields and their role in semi-automated interpretation methods. Geophys. Prospect., 57, 4, 507-516, doi: 10.1111/j.1365-2478.2008.00780.x.

Pašteka R., Karcol R., Pašiaková M., Pánisová J., Kušnirák D., Béreš J., 2011: Depth Estimation of Microgravity Anomalies Sources by Means of Regularized Downward 
Continuation and Euler Deconvolution. Proceedings from the 73rd EAGE Conference \& Exhibition, Vienna, Austria, 23-26 May 2011, 5 p., doi : 10.3997/2214-4609 .20149399.

Potent modelling software, Geophysical Software Solutions, User's guide, version v4.16.07, Manuscript, online, accessed 2019-11-17, available from: http://www.geoss.com.au /downloads.html.

Putiška R., Nikolaj M., Dostál I., Kušnirák D., 2012: Determination of cavities using electrical resistivity tomography. Contrib. Geophys. Geod., 42, 2, 201-211, doi : 10 .2478/v10126-012-0018-3.

Reid A. B., Allsop J. M., Granser H., Millet A. J., Somerton I. W., 1990: Magnetic interpretation in three dimensions using Euler deconvolution. Geophysics, 55, 1, 80-91, doi: 10.1190/1.1442774.

Sandmeier K. J., 2019: ReflexW Vers. 9, Manual. SandmeierGeo, Karlsruhe, Manuscript, online, accessed 2019-11-18, available from: https://www.sandmeier-geo.de/down load.html.

Sarlak B., Aghajani H., 2017: Archaeological investigations at Tepe Hissar-Damghan using Gravity and Magnetics methods. J. Res. Archaeom., 2, 2, 19-34, doi : 10.29252/ jra.2.2.19.

Slepak Z., 1997: Complex geophysical investigations for studying the cultural layer and remains of ancient buildings in the territory of Kazan Kremlin, Kazan, Republic of Tatarstan, Russia. Archaeol. Prospect., 4, 4, 207-218, doi : 10.1002/(SICI) 1099-07 63(199712) $4: 4<207:$ : AID-ARP83>3.0.CO;2-L.

Zieliński A., Łyskowski M., Mazurkiewicz E., Lubarska K. W., 2019: Burial crypts in solid rock - a geophysical case study of a small church with a unique polychrome in Szydłów (S Poland). Geol. Geophys. Env., 45, 2, 89-97, doi : 10.7494/geol.2019 .45 .2 .89 . 